\title{
O entalhe virtual da Luteria em tempos de pandemia
}

\author{
The virtual engraving of the Lutherie in the \\ pandemic times \\ pandemic times
}
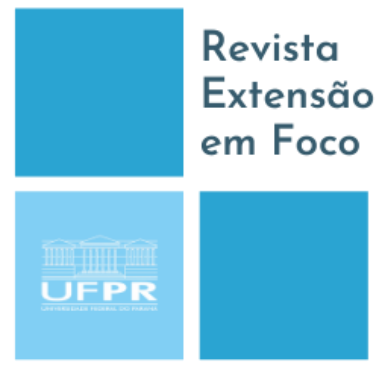

ISSN $2358-7180$

\section{Thiago Corrêa de Freitas ${ }^{1}$, Igor Mottinha Fomin², Bogdan Skorupa Ribeiro dos Santos ${ }^{3}$, Bruno Matheus Nicolini ${ }^{4}$, Matheus Ubiratan Bianco Frote ${ }^{5}$}

\begin{abstract}
RESUMO
O presente trabalho tem por objetivo ser o registro, junto a reflexões, do projeto "Luteria em tempos de pandemia", o qual foi contemplado em edital emergencial específico da Universidade Federal do Paraná no ano de 2020. O termo luteria, de forma simples, designa atividade relativa à construção de instrumentos musicais e o termo luthier designa aquele que atua com Luteria. $\mathrm{O}$ intuito inicial do projeto foi a promoção de atividades dialógicas com luthiers atuantes no Brasil e no exterior através de transmissões ao vivo, visando preencher, ao menos parcialmente, a lacuna causada pela suspensão de atividades de ensino de Luteria, fundamentalmente presenciais. Buscou-se também a promoção de uma maior interação entre os luthiers do Brasil, facilitando as trocas de experiências profissionais e a promoção de um encontro semanal entre colegas, amigos e conhecidos, visando o bem-estar pessoal dos participantes. Para tanto, utilizou-se um modelo de entrevista, completamente virtual, em duas partes, onde o entrevistador conduzia a primeira parte e, na segunda parte, as perguntas dos participantes eram respondidas. Desta forma foram realizadas vinte entrevistas, as quais atingiram os objetivos propostos e, indiretamente também serviram como registro histórico aberto da Luteria brasileira da atualidade, uma vez que as entrevistas foram disponibilizadas de maneira aberta ao público geral.
\end{abstract}

Palavras-chave: Formação Profissional. Luteria. Instrumentos musicais. Integração universidade-sociedade. Aprendizagem de artes e ofícios.

\section{ABSTRACT}

The purpose of this paper is to register, with reflections, the project "Luteria in pandemic times", which was contemplated in a emergency call notice from Federal University of Paraná in 2020. The lutherie term, in a simple way, designates musical instrument crafting activity, and the term luthier designates the one who practices lutherie. The initial purpose of the project was to promote dialogical activities with luthiers working in Brazil and abroad through live streams, aiming to fill, at least partially, the gap caused by the suspension of lutherie teaching activities, mainly on-site ones. It was sought to promote greater interaction between luthiers in Brazil, facilitating the exchange of professional experiences and to promote a weekly meeting between colleagues, friends and acquaintances, aiming at the participants' welfare. For that, it was used an interview model, completely virtual, in two parts, where the interviewer conducted the first part and, in the second part, the participants' questions were answered. Thus, twenty interviews were carried out, which achieved the proposed objectives and, indirectly, also served as an open historical record of today's Brazilian Lutherie, since the interviews were broadcasted in an open way to the general public.

Keywords: Professional formation. Lutherie. Musical instruments. University-society integration. Learning arts and crafts. 


\section{INTRODUÇÃO E CONTEXTUALIZAÇÃO}

O primeiro semestre letivo do ano de 2020 foi interrompido pouco depois de seu início devido à disseminação do SARS-COV-19. Instaurado estado de pandemia, foram limitadas as atividades presenciais, assim como o acesso às instituições de ensino, também na Universidade Federal do Paraná, as aulas não puderam acontecer de forma geral. Aulas de caráter expositivo puderam ser adaptadas para modalidade de ensino remoto. $\mathrm{O}$ mesmo não pode acontecer com disciplinas e projetos de ensino que envolviam atividades práticas, o caso predominante no ensino de Luteria segundo Freitas (2019) e Almeida et al. (2020).

Para Roque (2003), a Luteria compreende "a elaboração de instrumentos musicais acústicos de madeira construídos minuciosamente à mão". Os profissionais são chamados de luthier e, no caso do especialista na construção de arcos, archetier, termos que possuem origem francesa (LEHMANN, 2006, p.25). A utilização desses termos deve-se ao fato da França, em especial a cidade de Mirecourt, ter dado contribuições significativas para o ofício (DIDIER, 2005).

\footnotetext{
Luteria é a palavra em Português que designa a atividade de construir reparar e realizar manutenção em instrumentos musicais de cordas... Atualmente o termo também é utilizado para reportar-se à construção de cordofones elétricos, como guitarras, baixos elétricos, violinos elétricos, etc., bem como é aceito para produção artesanal de instrumentos de sopro, teclas e percussão (PEREIRA, 2019, p.100).
}

Talvez nenhum outro curso da Universidade Federal do Paraná tenha sido tão afetado quanto o Curso de Luteria pela impossibilidade do desenvolvimento do saber prático. A demanda pelo uso dos laboratórios é de 6 turnos que precisam caber em 5 dias letivos (FREITAS, 2019), isso apenas para as disciplinas de Construção e Entalhe, que são aquelas em

1 Doutor. Universidade Federal do Paraná (UFPR), Curitiba, Paraná, Brasil. E-mail:tcf@ufpr.br. Orcid: https://orcid.org/0000-0001-5174-1130

2 Mestre. Universidade Federal do Paraná (UFPR), Curitiba, Paraná, Brasil. E-mail:fomin@ufpr.br. Orcid: https://orcid.org/0000-0003-2039-2307

3 Mestre. Café com Luteria, Curitiba/Ponta Grossa, Paraná, Brasil. E-mail:bogdanskorupa@gmail.com. Orcid: https://orcid.org/0000-0002-9751-001X

4 Graduando. Universidade Federal do Paraná (UFPR), Curitiba, Paraná, Brasil. E-mail: nicolini1999@gmail.com. Orcid: https://orcid.org/0000-0003-2046-1843

5 Graduando. Universidade Federal do Paraná (UFPR), Curitiba, Paraná, Brasil. E-mail:

matheus_frote@hotmail.com. Orcid: https://orcid.org/0000-0001-7017-9526 
que o discente estuda especificamente a construção de instrumentos musicais, embora não sejam as únicas que necessitam de prática laboratorial.

Situação semelhante se passou com outros cursos de Luteria pelo Brasil como o do Conservatório de Tatuí (ALMEIDA, 2019), em São Paulo e pelo mundo, como o caso dos cursos de Luteria da Universidad Nacional de Tucumán, na Argentina (LEIVA, 2019) e, do Instituto Nacional de Belas Artes em Querétaro (PEÑA, 2018), México. Todos esses possuem ampla carga de atividades práticas laboratoriais.

Os meios virtuais utilizados para aulas expositivas se mostram insuficientes para igualar as vivências práticas como aconteciam antes da pandemia, sendo indispensáveis ao desenvolvimento de habilidades e percepções próprias do fazer, visto que, as atividades de construção, restauração e manutenção dependem de um contato direto dos estudantes com materiais, ferramentas e maquinários específicos conforme discutido por Freitas et al. (2017).

Une-se a estas dificuldades, próprias do aprendizado, a indisponibilidade de tais insumos em geral, de difícil aquisição e alto custo. Muitos estudantes, especialmente aqueles que começam o curso, não possuem contato prévio com o trabalho em madeira, além disso, não dispõem de um espaço adequado ao desenvolvimento de atividades práticas, desta forma, não poderiam acompanhar atividades práticas em suas casas.

Se a falta de infraestrutura não pode ser resolvida facilmente, nem mesmo para os estudantes mais avançados, que, assim como profissionais em início de carreira, sentem o peso de adquirir o ferramental e maquinário para exercerem a profissão de luthier, ao menos, conhecer a realidade dos profissionais atuantes há mais tempo seria de grande proveito para quem estuda ou admira essa arte.

Neste sentido, proporcionar o acesso à informações específicas do universo da Luteria pode facilitar a obtenção de conhecimentos importantes através da intermediação do contato dos estudantes com profissionais atuantes na área.

Cabe ressaltar que este momento atípico e delicado exige pensar na importância das relações interpessoais e de convívio. De acordo com Lima (2020), entre as diversas prescrições de condutas com a finalidade de melhorar a qualidade de vida e atenuar os efeitos psicológicos do isolamento, está relacionado: "manter contato telefônico ou online com familiares e amigos". $\mathrm{O}$ contato entre colegas de uma mesma área propicia trocas de experiências, mas também uma 
sensação de pertencimento, que pode ter um papel importante para a saúde mental de pessoas em isolamento ou distanciamento social.

Com isso, propôs-se uma série de entrevistas transmitidas ao vivo pelo Instagram de uma revista virtual com propósito de divulgação de Luteria. A revista foi criada por egressos da Universidade Federal do Paraná e, atualmente, envolve dois professores em suas atividades. Este contato próximo entre a Universidade Federal do Paraná e a revista contempla princípios extensionistas em suas atividades, e em específico no projeto aqui relatado, descritos na resolução que dispõem sobre as atividades institucionais de extensão (UNIVERSIDADE FEDERAL DO PARANÁ, 2019).

A relação entre os princípios institucionais de extensão e as atividades desenvolvidas no projeto podem ser elencadas nos quatro tópicos seguintes:

a) Impacto e transformação social, que visa o estabelecimento de inter-relação entre a Universidade Federal do Paraná, sua comunidade e os demais segmentos da sociedade para uma atuação transformadora, contribuindo para a formação acadêmica, os interesses e necessidades sociais, o desenvolvimento regional, econômico, social, ambiental, cultural e o aprimoramento de políticas públicas - uma vez que permite tanto à equipe quanto ao público estabelecer relações mútuas dentro da comunidade da Luteria, formada por profissionais, estudantes e docentes; contribuindo também para a formação acadêmica em momento de suspensão de atividades de ensino; aproximando diversas realidades sociais e de políticas públicas voltadas ao ensino de Luteria, posto que os principais centros de formação Profissional e Tecnológica no Brasil são mantidos ou ligados ao fomento pelo Estado;

b) Interação dialógica, que visa o estabelecimento e desenvolvimento de relação entre a Universidade Federal do Paraná, sua comunidade e os demais segmentos da sociedade por meio do diálogo e da troca de saberes - uma vez que tem por premissa o diálogo com pessoas de destacada atuação na área da Luteria, visando a troca de informações, saberes e experiências;

c) Multidisciplinaridade, interdisciplinaridade ou transdisciplinaridade, ou ainda a multiprofissionalidade, que visa o estabelecimento de inter-relação ou integração de modelos, conceitos e metodologias, oriundos de várias disciplinas e áreas de conhecimento, bem como a construção de alianças intersetoriais, interorganizacionais e interprofissionais, para o atendimento às demandas formativas e sociais - uma vez que é da própria natureza da Luteria 
relacionar temas que vão desde a divulgação de informações, aquisição de materiais e contato com diferentes profissionais, a princípio, com músicos; também estabelece relações com instituições de formação de ensino de Luteria em nível técnico, atuação e pesquisa, levando a uma integração vertical da Luteria;

d) Indissociabilidade entre ensino, pesquisa e extensão, que consiste no vínculo da extensão universitária ao processo de formação de pessoas e de geração de conhecimento podendo envolver servidores técnico-administrativos, discentes de pós-graduação e comunidade externa e necessariamente docentes e discentes, cursos técnicos ou de graduação, da Universidade Federal do Paraná, durante todo o período de vigência da atividade - uma vez que a equipe proponente é composta por docentes, discentes e membros da comunidade da Luteria externa à Universidade Federal do Paraná, os quais levam informações que complementam o conhecimento de profissionais, registram as experiências relatadas por tais profissionais de forma metódica e ajudam na formação dos estudantes que estão com atividades de ensino suspensas.

\section{METODOLOGIA}

Adotou-se o modelo de entrevista transmitida ao vivo no formato de live, a plataforma escolhida para a transmissão foi o Instagram, através do perfil da Café com Luteria, uma revista brasileira de divulgação de Luteria. A escolha do Instagram deve-se principalmente a dois fatos, sendo o primeiro, pela facilidade e popularidade na produção de lives e, o segundo, pelo fato deste perfil possuir mais de mil seguidores.

Dentre esses, majoritariamente, encontram-se luthiers, archetiers, estudantes de Luteria e instrumentistas, ou seja, o público-alvo da proposta extensionista apresentada ao edital emergencial da Universidade Federal do Paraná. As lives foram estruturadas em um padrão de duas partes de $1 \mathrm{~h}$ cada, em função da limitação de tempo em $1 \mathrm{~h}$ pela plataforma e também por questões de organização.

A primeira parte foi dedicada à explanação sobre o tema da live por parte do convidado, através de um diálogo conduzido pelo autor Bogdan Skorupa. A segunda parte consistia em uma forma de diálogo onde predominava a interação com o público, o qual tinha liberdade para fazer perguntas e intervenções (por chat), as quais eram colocadas ao convidado pelo mediador. 
Não houve seleção prévia de questões do público. A mediação teve por foco questões relacionadas ao tema da live.

Convencionou-se às segundas-feiras, $18 \mathrm{~h}$, como dia da semana e horário para as transmissões. Exceções foram feitas às situações onde o convidado encontrava-se em local com fuso horário diferente, ocasião quando foi buscado um horário mais confortável para o mesmo.

Figura 1 - Divulgação para a live de Saulo Dantas-Barreto, sobre a história da Luteria no Brasil.

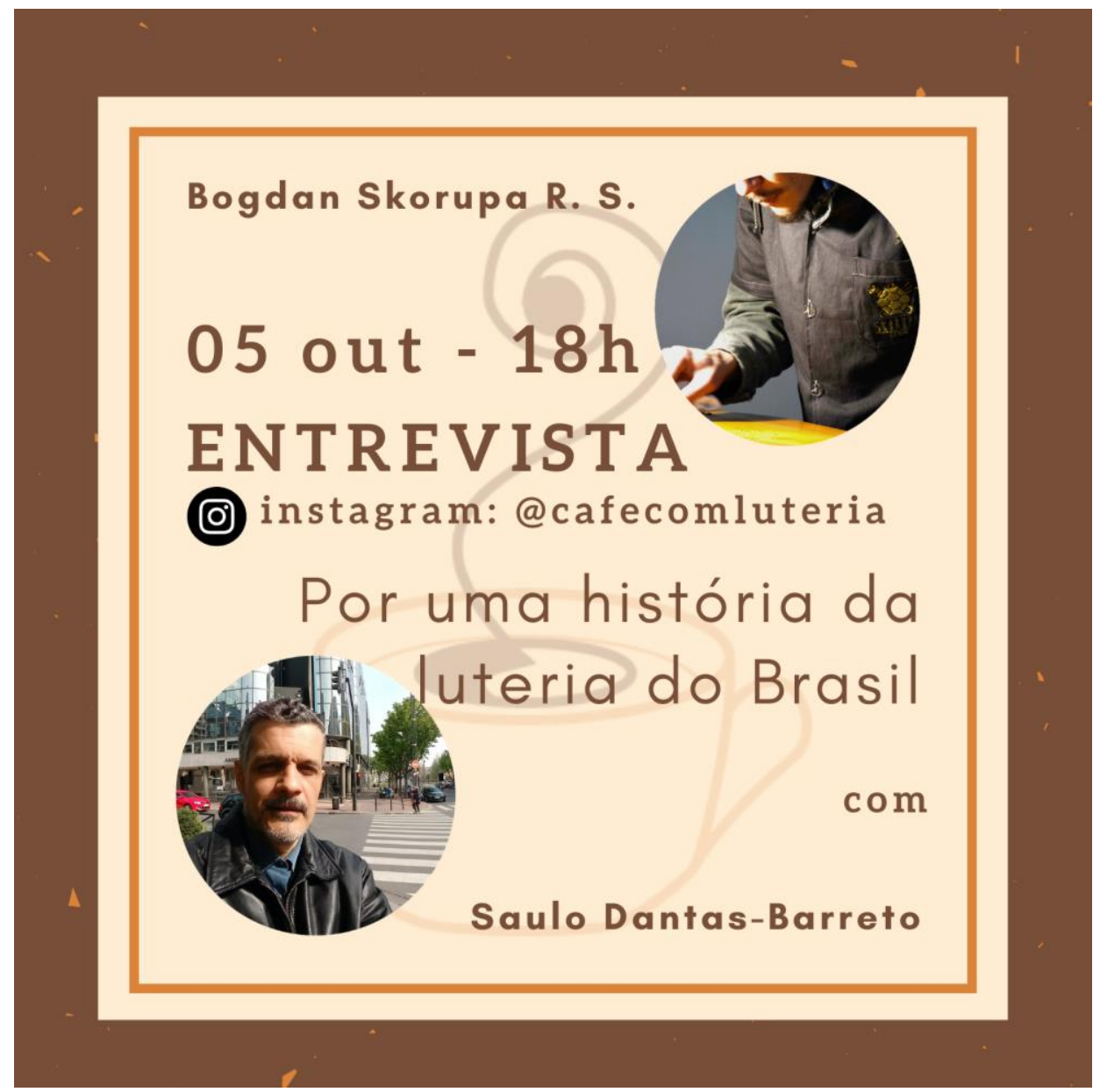

Fonte: OS AUTORES (2020).

A Figura 1 mostra um exemplo de arte para a chamada e divulgação das lives, as quais eram divulgadas com, pelo menos, uma semana de antecedência. Após a transmissão, a live foi publicada com acesso público, permitindo acessos posteriores, a qualquer tempo. Iniciou-se um processo, ainda não concluído, de edição e transcrição das lives visando a produção de textos e 
podcasts com o objetivo de ampliar ainda mais o alcance do conteúdo. A atuação na Luteria, em diversos níveis, em um tempo considerável, permitiu aos proponentes uma inserção na comunidade envolvida pela Luteria brasileira. Favoreceu a formação de uma rede de amigos e conhecidos com reconhecida atuação profissional tanto no Brasil quanto no estrangeiro.

A seleção dos entrevistados aconteceu através de indicação de colegas de profissão e investigação da trajetória profissional e pública da pessoa a ser convidada. Evidenciou-se o funcionamento em rede da Luteria, especialmente, ao notar profissionais que mantêm, pelo menos, vínculos profissionais e troca de informações, o que permitiu aos proponentes uma inserção nessa comunidade. Por fim, os convidados aceitaram a participação em função desta rede, da disponibilidade e interesse na participação do projeto, resultando em 20 profissionais entrevistados no ano de 2020.

Ainda antes da realização das entrevistas, criou-se uma lista com luthiers atuantes no Brasil, especialmente, construtores, mantenedores e restauradores de violinos e violões clássicos, essencialmente oriundos de indicações de profissionais atuantes na Luteria e das investigações de sua atuação. Pelo menos duas semanas antes da realização da entrevista, entrou-se em contato com luthiers selecionados a partir dessa lista (por chamada telefônica e/ou mensagens em rede social). Os critérios usados para esta seleção foram: abnegação; senso de comunidade; coerência entre dizer e fazer; honestidade acerca de sua produção; responsabilidade pelas informações; e transparência.

A avaliação se deu através do contato com o potencial entrevistado via telefone ou rede social, pedindo que contasse a sua trajetória na Luteria até chegar no momento atual. Foi complementada pela referida investigação dos trabalhos realizados pelo autor, bem como sua relação em geral com colegas. Existe uma particular importância nisto, visto que a Luteria muito dificilmente poderia ser aprendida e praticada pelo indivíduo isolado ou autodidata em sua vida toda, mas este precisa estar em contato com a tradição secular, por vezes, passada de mestre(s) a aprendiz ou referenciada em livros e pesquisas - considerando que é uma profissão transdisciplinar, complexa e consistida de diferentes escolas estéticas e de grande riqueza de técnicas e ferramentas; bem como é estabelecida o suficiente para possuir critérios universalizados para defini-la, caso das escolas em diferentes países possuírem conteúdos e livros de referência semelhantes.

A abnegação foi avaliada de forma a evidenciar se o potencial entrevistado se abstinha de 
ideais egoístas em prol, no caso, do desenvolvimento da Luteria; algo percebido durante a conversa, tão logo pela disposição em participar de um evento online não remunerado e aberto ao público, inclusive, colegas e aprendizes da profissão. Também foi usado como indicador para transparência como a pessoa relatava informações diante de questionamentos apresentados, permitindo que algumas delas fossem ocultadas quando houvesse necessidade de proteção de informações relativas a processos industriais e patentes.

Avaliou-se os vínculos que o potencial entrevistado tinha com mestres e colegas. São pessoas com quem aprendeu, aprende e mantém contato de troca aberta de informações. Isto mostra, particularmente, se o profissional está em atividade e tem um trabalho considerado de relevância pelos seus pares. O cruzamento de informações passadas pelo potencial entrevistado, informações obtidas em plataformas de busca da internet e relatadas por colegas também permitiu avaliar a responsabilização pelas informações prestadas e a transparência. Convém ressaltar que não é comum que o luthier se utilize da plataforma Lattes, por exemplo, para apresentar sua formação e produção, assim como não existe uma entidade de classe do ofício, para fornecer eventuais informações a respeito de profissionais atuantes.

A coerência entre dizer e fazer pode ser avaliada em relação ao que o potencial entrevistado já disse em entrevistas, vídeos, materiais escritos, comparando isto com o que o luthier produz profissionalmente. Une-se a isto a honestidade sobre a produção: se o profissional declara que obras de sua autoria realmente o são. Foram avaliados casos de problemas entre o profissional e clientes, declarados pelo próprio potencial entrevistado, ao mesmo tempo que foram pesquisados possíveis processos judiciais atrelados ao nome e registro civil, acessíveis por plataformas de buscas do próprio sítio da Justiça Federal brasileira.

Informações sobre a trajetória dos luthiers foram obtidas por meio das anotações feitas durante as chamadas telefônicas (10 dos luthiers preferiram este contato, mantendo conversas de, pelo menos, uma hora de duração cada) e utilizando os registros de mensagens em rede social. Todas as informações foram transformadas em textos sintéticos de apresentação da trajetória profissional, que foram usados, por exemplo, na descrição das postagens do Instagram que anunciavam a data da próxima entrevista. Estes textos foram revisados e conferidos pelo próprio convidado-entrevistado, garantindo a veracidade das informações apresentadas.

Outras informações obtidas durante as conversas foram registradas, contribuindo para escolher temas a serem abordados em cada entrevista e a elaborar um roteiro com perguntas 
pontuais por parte do entrevistador. Além de auxiliar na condução, as informações contribuíram para situar discussões, com a possibilidade de verificar dados e referências de trabalhos em Luteria, evidências históricas, questões específicas ao trabalho do luthier, etc. A temática das lives resumiu-se aos seguintes assuntos: construção de violinos, construção de arcos, construção de violões, formação em Luteria, atuação em Luteria, história da Luteria e pesquisa em Luteria. Não se seguiu uma ordem de assuntos entre as lives em função da necessidade de adequá-las à disponibilidade dos convidados.

\section{RESULTADOS E IMPACTOS}

A partir da metodologia descrita, foi possível realizar um conjunto de vinte lives, totalizando $40 \mathrm{~h}$ de discussões relacionadas aos mais diversos assuntos dentro da temática abordada pelos convidados, os quais estão disponíveis ao público em geral em www.instagram.com/cafecomluteria/. O conteúdo disponível, assim como a data da transmissão original, nome do convidado, tema e local de atuação do mesmo encontram-se sintetizados no Quadro 1. O alcance das transmissões foi considerado satisfatório, uma vez que entre 50 a 100 pessoas participaram, em partes ou integralmente, de cada uma das lives, interagindo com perguntas e comentários. Algo que implica em um número total de 1000 a 2000 participações. Já o acesso aos registros gravados, conforme o tema, variou entre 150 a 500 visualizações por live.

Embora não fosse a intenção inicial do projeto, o conjunto de lives acabou por ser também um registro histórico de parte dos luthiers e archetiers brasileiros da atualidade. Aqui convém ressaltar que os registros de aspectos históricos da Luteria no Brasil são mínimos salvo poucos casos específicos, como por exemplo, os trabalhos de Dantas-Barreto (2020a, 2020b), Pereira (2019) e Bergmann (2014). Foram registrados profissionais de sete estados do Brasil (ES, MG, PB, PE, PR, RJ e SP) e, além do Brasil, atuando em quatro outros países: Alemanha, França, Itália e Malta. Tal registro por si só poderá servir para estudos futuros com abordagens diversas, como histórica, social, cultural e educacional, entre outras. As reflexões oriundas desse trabalho também ampliaram as ideias possíveis para atividades a serem desenvolvidas 
quando da curricularização da extensão e sua real efetivação.

Quadro 1 - Entrevistas realizadas ao vivo

\begin{tabular}{|c|c|c|c|}
\hline Data & Tema & Luthier & Local de atuação \\
\hline $20 / 04 / 2020$ & Restauração de violinos & Rudson di Cavalcanti & São Paulo - SP \\
\hline $27 / 04 / 2020$ & Critérios ao criar um violino & $\begin{array}{c}\text { Vlamir Devanei } \\
\text { Ramos }\end{array}$ & Tatuí - SP \\
\hline $04 / 05 / 2020$ & $\mathrm{O}$ arco pelo archetier & Igor Mottinha Fomin & Curitiba - PR \\
\hline $11 / 05 / 2020$ & Estudar Luteria na Itália & Marcelo Gonçalves & Milão - Itália \\
\hline $18 / 05 / 2020$ & Luteria de João Neiva & Julio Cesar Vesper & João Neiva - ES \\
\hline $25 / 05 / 2020$ & $\begin{array}{l}\text { Construção de violino como } \\
\text { estudo }\end{array}$ & Vinicius Fachinetti & Tatuí - SP \\
\hline $01 / 06 / 2020$ & O cuidado com seu nicho & Fábio Vanini & São Paulo - SP \\
\hline $08 / 06 / 2020$ & Relação entre músico e luthier & Tulio Lima & Petrópolis - RJ \\
\hline $15 / 06 / 2020$ & $\begin{array}{l}\text { Violino: construção a longo } \\
\text { prazo }\end{array}$ & Gedson Bravim & São João del-Rei - MG \\
\hline $22 / 06 / 2020$ & Influência do clima na Luteria & $\begin{array}{l}\text { Leandro Henrique } \\
\text { Merino Mombach }\end{array}$ & Curitiba - PR \\
\hline $29 / 06 / 2020$ & Violão em construção & Bruno Galli Nacli & Lençóis Paulista - SP \\
\hline $06 / 07 / 2020$ & Música em favor da Luteria & Marcos Pandolfi & João Neiva - ES \\
\hline $13 / 07 / 2020$ & $\begin{array}{c}\mathrm{O} \text { arco como provedor na } \\
\text { história da Luteria }\end{array}$ & Renato Casara & Brasil/Alemanha \\
\hline $20 / 07 / 2020$ & Violino alemão sem preconceito & Andreas Hellmann & Munique -Alemanha \\
\hline $03 / 08 / 2020$ & Luteria como razão social & $\begin{array}{l}\text { Carlos Alberto } \\
\text { Gomes Filho }\end{array}$ & Recife - PE \\
\hline $10 / 08 / 2020$ & $\begin{array}{l}\text { Construção de arcos e seus } \\
\text { acessórios }\end{array}$ & Henry Guerra & Paris - França \\
\hline $17 / 08 / 2020$ & Rabecas e violinos metódicos & Wilfred Amaral & João Pessoa - PB \\
\hline $24 / 08 / 2020$ & Vida de luthier em Cremona & Ednei Zuccati & Malta \\
\hline $28 / 09 / 2020$ & Estilo e estética na Luteria & Fernando Fagundes & São Paulo - SP \\
\hline $05 / 10 / 2020$ & $\begin{array}{c}\text { Por uma história da Luteria do } \\
\text { Brasil }\end{array}$ & Saulo Dantas-Barreto & São Paulo - SP \\
\hline
\end{tabular}

Fonte: Autores (2021).

O processo descrito na metodologia permitiu criar um registro de informações em diferentes níveis. Primeiro, num viés enciclopédico, com uma listagem de 95 luthiers (envolvidos com as áreas de violinos e violões) e 5 cursos que tivemos conhecimento e que estão em atividade. Em particular, essa quase centena de luthiers é bastante representativa, uma vez que uma estimativa de Ghobril et al. (2019) aponta ao redor de 350 profissionais atuando no Brasil. Foi registrada cidade, estado, país de atuação, contato e área de atuação, dentro das possibilidades de obtenção de informações em ferramentas de busca pela internet e contato 
direto por mensagens em redes sociais.

Segundo, no sentido biográfico, foi possível ouvir e registrar acontecimentos que esclarecem o percurso profissional dos luthiers selecionados e que aceitaram participar das entrevistas. Isto aconteceu através de chamadas telefônicas e mensagens trocadas em redes sociais. As anotações feitas em tempo real foram transformadas em textos sintéticos de apresentação dos entrevistados. Estes textos ficaram registrados publicamente no perfil da Café com Luteria no Instagram, na descrição das postagens cuja função era anunciar uma próxima entrevista a ser realizada. Todos os luthiers que poderiam ser entrevistados, a partir da primeira listagem, foram avaliados sob critérios anteriormente descritos.

Por último, conseguiu-se registrar informações no sentido do discurso argumentativo em torno de um assunto. A perspectiva deste discurso é do próprio praticante, cuja fala em relação à práxis nem sempre é registrada ou revelada (FREITAS et. al. 2017). Os discursos dos entrevistados sobre os temas escolhidos ficaram registrados na íntegra no perfil do Instagram. Os registros em áudio e vídeo também foram baixados e transformados em outros conteúdos, buscando favorecer o acesso ao grande público.

Neste sentido, destaca-se um conteúdo produzido: um episódio (disponibilizado na plataforma Anchor, que redistribui o podcast em diversos servidores de podcasts e áudios, sendo o mais conhecido deles o Spotify) de uma série de podcasts. Este primeiro episódio foi produzido com base no áudio da entrevista com Rudson di Cavalcanti, que foi editada e sonorizada. Submetido a edital de incentivo de cultura, recebeu, ainda em 2020, premiação como atividade de valor cultural musical.

O público que assistiu as entrevistas apresentou participação constante durante as lives, algo notado pelo chat que a plataforma Instagram oferece. Os constantes questionamentos no decorrer das entrevistas mostraram acertada a sua realização em duas partes de $1 \mathrm{~h}$ cada, sendo dedicada a segunda parte para respondê-los.

Depois das entrevistas, tanto os entrevistados quanto o público apresentaram feedback sobre a experiência. Os vinte entrevistados demonstraram satisfação com a apresentação do conteúdo e sua qualidade no sentido de informar sobre o assunto. A cada final de entrevista, pessoas do público das entrevistas enviavam mensagens particulares por redes sociais, 
manifestando pedidos por assuntos e também apoio à realização do projeto.

Vale ressaltar o caso onde um luthier que acompanhou a entrevista de um colega, ao final da live, enviou mensagem dizendo que reconsideraria a visão que tinha sobre a pessoa entrevistada. Essa situação demonstra um fenômeno de isolamento dos luthiers em grupos de convivência profissional ou pessoal.

Na perspectiva do funcionamento da Luteria em rede, ainda que em pequena escala, podese contribuir para quebrar barreiras para a troca de informações entre colegas, algo ainda pouco comum no Brasil (ALMEIDA e PIRES, 2012). Entende-se que as entrevistas atuaram, portanto, no sentido da mediação de informações e contatos.

Embora igualmente não contemplada na proposta inicial, a divulgação de Ciência \& Tecnologia mostrou-se presente em, pelo menos, três das lives, nas quais os temas versados estavam ligados a estudos em nível de pós-graduação por parte dos entrevistados. Por ordem cronológica, temos a terceira entrevista, que trouxe para o público uma experiência com a utilização de madeiras alternativas ao pau-brasil na confecção de $\operatorname{arcos}$ de violino (FOMIN, 2017). Na sequência, uma discussão sobre a influência do clima na Luteria (MOMBACH, 2018) e, por fim, resultados de uma investigação a respeito dos luthiers atuantes no Rio de Janeiro na época do Império, o contexto social e legado deixado para a posteridade (DANTASBARRETO, 2020a e 2020b).

As três entrevistas demonstram a importância da pesquisa realizada pelos luthiers, uma vez que seus pontos de vista, em função da profissão, experiência e vivência, não serão contemplados por pesquisadores de outras áreas.

\section{CONCLUSÃO}

A partir da busca pelos autores de uma alternativa para o hiato deixado aos estudantes de Luteria em decorrência da pandemia, objetivou-se facilitar o conhecimento da realidade dos profissionais da área por meio da interação destes com a comunidade interna e externa nos meios digitais. Desta forma, algumas consequências puderam ser observadas.

Ao menos parte daquilo que um estudante vislumbra sobre a profissão e suas particularidades pode ficar mais claro. Houve também divulgação de Ciência \& Tecnologia em, 
pelo menos, três das lives, pois os entrevistados trataram, entre outros temas, de trabalhos acadêmicos realizados, cujo foco era a Luteria de alguma maneira.

Esse aspecto é bastante relevante, uma vez que abordagens científicas à Luteria ainda encontram-se em estágio incipiente no Brasil. Em particular, dar ênfase a esse tipo de produção de conhecimento é relevante para alunos e egressos da Universidade Federal do Paraná que desejam realizar algum tipo de aperfeiçoamento em algum programa de pós-graduação. Além disso, foi alcançado o público profissional através de troca de informações e interação que, até onde se sabe, não ocorria de maneira tão significativa, mesmo quando em tempos de eventos presenciais, os quais, diga-se de passagem, são ainda bastante pouco frequentes.

Além de atingir o público de luthiers profissionais, dois grandes registros foram realizados: o arquivo videográfico dos que apresentaram seus temas de interesse, ideias e filosofias de trabalho; e o levantamento catalográfico de outros tantos profissionais com quem se dialogou durante o projeto, permitindo um levantamento atualizado de aproximadamente um terço dos luthiers atuantes no país. Igualmente relevante e importante foi a possibilidade de dialogar com luthiers brasileiros atuantes na Europa, visto que demonstra a viabilidade de uma carreira internacional.

Neste trabalho ficou notória a interação dialógica extensionista, dado que, além da comunicação ativa com o público ao qual foram propostas as ações do projeto, também foi possível observar aspectos tanto pelo ponto de vista extensionista quanto da pesquisa nas atividades desenvolvidas na instituição. Dentre estes, pode-se destacar: a continuidade dessas atividades de entrevistas em forma de lives, em virtude da incerteza sobre a realização de reuniões presenciais, que até o momento parecem improváveis; e a continuidade da pesquisa de levantamento dos profissionais da Luteria e Arquetaria que atuam no Brasil. Ambos devem promover uma maior integração da área e destacar protagonismo junto à Universidade Federal do Paraná.

Também foi possível aos autores ampliarem o seu conhecimento e entendimento sobre a Luteria e os luthiers do Brasil, suas particularidades, expoentes, origens e demais nuances tão 
características de um país de dimensões continentais.

\section{AGRADECIMENTOS}

Os autores agradecem à Universidade Federal do Paraná pelo apoio e financiamento parcial do projeto através da cessão de bolsas para atuação discente em edital específico para a situação de pandemia. Agradecemos também, explicitamente, aos seguintes luthiers e archetiers que contribuíram com seu tempo e compartilharam seus conhecimentos, sem os quais o projeto não lograria êxito: Andreas Hellmann, Bruno Galli Nacli, Carlos Alberto Gomes Filho, Ednei Zuccati, Fabio Vanini, Fernando Fagundes, Gedson Bravim, Henry Guerra, Igor Mottinha Fomin, Julio Cesar Vesper, Leandro Henrique Merino Mombach, Marcelo Gonçalves, Marcos Pandolfi, Renato Casara, Rudson di Cavalcanti, Saulo Dantas-Barreto, Tulio Lima, Vinicius Fachinetti, Vlamir Devanei Ramos e Wilfred Amaral. Agradecemos também aos demais luthiers e archetiers contatados, os quais se dispuseram a contribuir com o projeto mas ainda não foram entrevistados no âmbito inicial do projeto, os quais poderão contribuir na versão futura deste trabalho como projeto de extensão padrão.

\section{REFERÊNCIAS}

ALMEIDA, G. M; PIRES, A. A arte da luteria no Brasil. Revista Educação, Guarulhos, v. 7, n. 1, p. 68-76, 2012. Disponível em: <http://revistas.ung.br/index.php/ educacao/article/view/ 1002>. Acesso em 10 abr. 2021.

BERGMANN FILHO, J. Museu dos Instrumentos Musicais. 1. ed. Curitiba: Editora UFPR, 2014.

DANTAS-BARRETO, S. Quando a modernidade destrói o futuro. Revista Café com Luteria, Curitiba, n. 4, p. 10-13, mar. 2020. Disponível em: <https://issuu.com/ cafecomluteria/docs/cafe_com_luteria._n4.>. Acesso em 22 mar. 2021.

DANTAS-BARRETO, S. Violinos imperiais: luteria brasileira no século XIX. 143 p. Dissertação (Mestrado em Música) - Instituto de Artes, Unicamp. Campinas, 2020. Disponível 
em: 〈http://repositorio.unicamp.br/handle/REPOSIP/357994>. Acesso em 12 abr. 2021.

DIDIER, J. Manufactures et maîtres-luthiers: Mirecourt 1919 - 1968. Bar le Duc: Saint-Paul Imprimeur, 2005.

FOMIN, I. M. A madeira de ipê (Handroanthus spp.) para arcos de violino: propriedades e avaliação de desempenho técnico. 87 p. Dissertação (Mestrado em Engenharia Florestal) - Setor de Ciências Agrárias, UFPR. Curitiba, 2017. Disponível em: <https://acervodigital.ufpr.br/handle/1884/47139>. Acesso em 12 abr. 2021.

FREITAS, T. C. Uma década de luteria na Universidade Federal do Paraná. Revista Café com Luteria, Curitiba, n. 2, p. 11-16, abr. 2019. Disponível em: $<$ https://issuu.com/cafecomluteria/docs/cafecomluteria.n02.22.04.2019). Acesso em 5 abr. 2021.

FREITAS, T. C.; ZACZÉSKI, M.; FOMIN, I. M.; SANTOS, B. S. R. Violão na luteria UFPR: ensino da construção e pesquisa sobre o instrumento. In: IX SIMPÓSIO ACADÊMICO DE VIOLÃO DA EMBAP. Curitiba, 2017. p. 100 -106. Disponível em: <http://www.embap.pr.gov.br/arquivos/File/2017/SIMPOSIO_VIOLAO/Anais_IX_SAVEmb ap_com_capa_final.pdf>. Acesso em 15 mar. 2021.

GHOBRIL, A. N.; SAKAMOTO, R.; DERDERIAN, P.; FURQUIM, C.; TADEU, L. Luthieria digital: Análise de uma oportunidade de negócios no mercado de serviços em instrumentos musicais. International Journal of Business \& Marketing (IJBMKT), São Paulo, v. 4, n. 1, P. 62-71, ago. 2019 . Disponível em: <http://www.ijbmkt.org/index.php/ ijbmkt/article/view/98/115>. Acesso em 10 abr. 2021.

LEHMANN, E. Dictionnaire de la lutherie et de l'archeterie. Spa: Les amis de la musique, 2006.

LEIVA, A. F. Escola de Luteria de Tucumán: $70^{\circ}$ aniversário de sua criação. Revista Café com Luteria, Curitiba, n. 3, p. 14-17, set. 2019. Disponível em: <https://issuu.com/ cafecomluteria/docs/cafe_com_luteria._n.3> $>$. Acesso em 5 abr. 2021.

LIMA, R. C. Distanciamento e isolamento sociais pela Covid-19 no Brasil: Impactos na saúde mental. Physis, Rio de Janeiro, v. 30, n. 2, e300214, 2020. Disponível em: <http:// www.scielo.br/scielo.php?script=sci_arttext\&pid=S0103-73312020000200313\&lng= 
en\&nrm=iso>. Acesso em 10 abr. 2021.

MOMBACH, L. H. M. Considerações climáticas na Luteria para exportação. DAPesquisa, v. 13, n. 20, p. 85-98, 2018. Disponível em: <https://www.revistas.udesc.br/ index.php/dapesquisa/article/view/1808312913202018085>. Acesso em 12 abr. 2021.

PEÑA, R. S.; GODÍNES, J. C. V. Los procesos formativos y curriculares de la Escuela de Laudería. 1. ed. Querétaro: Tecnológico Nacional de México, 2018. Disponível em: 〈https://ciidet.academia.edu/Departments/Investigaci\%C3\%B3n_Educativa/Documents>.

Acesso em 2 mar. 2021.

PEREIRA, R. M. Luteria: Coletânea de Termos Técnicos. 1. ed. Curitiba: Editora 
UFPR, 2019.

ROQUE, C. Luthiers: Artesãos Musicais Brasileiros. São Paulo: Edição do autor, 2003. UNIVERSIDADE FEDERAL DO PARANÁ. Conselho de Ensino Pesquisa e Extensão. Resolução $\mathrm{n}^{\text {o }} 57 / 2019$ de 13 de dezembro de 2019. Disponível em: <http://www.soc.ufpr.br/portal/resolucoes-do-cepe/>. Acesso em 12 jan. 2021.

Recebido em: 13 de abril de 2021. Aceito em: 20 de maio de 2021. 